\title{
A Glimpse at American Deaf Women's Sexuality
}

\author{
Hannah A. Joharchi' ${ }^{1}$, M. Diane Clark ${ }^{2}$ \\ ${ }^{1}$ Department of Psychology, Gallaudet University, Washington DC, USA \\ ${ }^{2}$ Department of Education, Gallaudet University, Washington DC, USA \\ Email: $\underline{\text { Hannah.Joharchi@gallaudet.edu }}$
}

Received 19 July 2014; revised 15 August 2014; accepted 12 September 2014

Copyright (C) 2014 by authors and Scientific Research Publishing Inc.

This work is licensed under the Creative Commons Attribution International License (CC BY). http://creativecommons.org/licenses/by/4.0/

(c) (i) Open Access

\begin{abstract}
Research regarding Deaf and hard of hearing individuals and their sexual satisfaction is almost nonexistent. Available research focuses on negative sexual behaviors and misinformation, as opposed to sexual satisfaction and well-being. Researchers used a model of generativity-what Erikson describes as success-a feeling of accomplishment, to explore positive aspects of Deaf sexuality. Someone experiencing generativity contributes to society in a meaningful and collaborative manner (Hamachek, 1990). The current study explored Deaf women, their generativity, and their sexuality. Five Deaf women were administered the revised Sexual Satisfaction Scale for Women (SSS-W) and discussed their sexual satisfaction in a semi-structured interview. Not only did participants display resiliency and generativity, but also they shared unique and positive aspects to Deaf sexuality.
\end{abstract}

\section{Keywords}

\section{Deaf, Hard of Hearing, Older, Sexual Satisfaction, Well-Being, Sexuality}

\section{Introduction}

Our understanding of sexuality in Deaf individuals is almost nonexistent. Available information focuses on myths, misunderstandings, and problems related to sexual health and behavior. Here we will look at the myths, explore the misunderstandings, and highlight how sexual problems have been investigated. This exploration will be followed by research looking at typical sexual development, leading to the current study about Deaf ${ }^{1}$ women's views of their own sexuality.

\footnotetext{
${ }^{1}$ When a D is used, as in Deaf, it refers to those members who identify as culturally Deaf. This usage is not a reflection of their audiological status.
} 


\section{Review of Literature}

\subsection{Myths}

Job (2004) reviewed 40 years of literature as it pertains to Deaf sexuality. Her review highlighted Griffiths proposed model of mythconceptions of the sexuality of disabled individuals, which she then demonstrated to be myths with regards to disabled people in general and Deaf people more specifically. The myths are:

1) People with developmental disabilities are eternal children and asexual.

2) People with developmental disabilities need to live in environments that restrict and inhibit their sexuality, to protect themselves and others.

3) People with developmental disabilities should not be provided with sex education, as it will only encourage inappropriate behavior.

4) People with developmental disabilities should be sterilized because they give birth to children who are also disabled.

5) People with developmental disabilities are sexually different from other people and are more likely to develop diverse, unusual, or deviant sexual behavior.

6) People with developmental disabilities are oversexed, promiscuous, sexually indiscriminate, dangerous, and you have to watch your children around them.

7) People with developmental disabilities cannot benefit from sexual counseling or treatment.

These myths reflect ideas that were explicit in the $20^{\text {th }}$ Century and may still be implicit in the $21^{\text {st }}$ Century. Given that society often views people with a disability from a medical model, where the individual needs to be “fixed” (Omansky \& Rosenblum, 2001; Rohleder \& Swartz, 2011), individuals with a disability are typically not referred to in a sexual manner. Rohleder and Swartz summarize research on individuals with a disability and note that there is a more paternalistic view of their sexuality. Here non-disabled individuals want to protect those with a disability and prevent harm (e.g., HIV, pre-marital sex, and sexual abuse) rather than expressing a concern regarding their sexual expression and enjoyment. As noted by Job, these myths influence us, limit our approaches and understanding of Deaf sexuality, and leave us without an understanding of Deaf sexuality.

\subsection{Misconceptions}

Importantly, information related to Deaf individuals tended to focus on the lack of sexual education. This view is likely related to Rohleder and Swartz's (Rohleder \& Swartz, 2011) comment that discussing sexuality for disabled individuals makes educators and people without a disability anxious. Interestingly enough, this work related to Deaf sexual education came from the 1970s, (Fitz-Gerald \& Fitz-Gerald, 1976, 1978; Neff, 1979; Robinson, 1979), 80s (Fitz-Gerald \& Fitz-Gerald, 1985), and 90s (Glannon, 1998; Joseph, Sawyer, \& Desmont, 1995; Swartz, 1993). Most of this research focused on Deaf sexual education as disseminated by educators and hearing parents. Given that many Deaf children were educated in residential schools during this time frame, this debate often led to limited or no sexual education, because parents are often not comfortable with schools teaching values (of which sex education is a component) leaving adolescents to use their peers as their main source of information about sex (Fitz-Gerald \& Fitz-Gerald, 1985; before the internet).

During the $20^{\text {th }}$ Century there was an attempt to control dating at residential schools, which was perceived to "distort the development of male-female relationships" (Meadow, 1976; Schlesinger \& Meadow, 1972, as cited in Jobs, 2004: p. 269). Research stated that only 10\% of these students from residential schools had "even had friendly relations with the opposite sex" (Shaul, 1981, as cited in Job, 2004: p. 269.) Schlesinger and Meadow (1972) reported that these 21-year olds had never had a date and that their "development of mature relations with members of the opposite sex, as preparation for intimacy leading to marriage and adulthood, is difficult under these conditions” (p. 147, as cited in Job, 2004: p. 269). A recent article (Kamieka \& Getch, 2001) reports that this state of affairs continued into the $21^{\text {st }}$ Century. These comments reflect the mythconceptions common at the time in regard to society's views of sexuality and disability. Today these ideas may shock or alarm a reader, but there is still limited research regarding the sexuality of Deaf individuals.

\subsection{Problems}

Research indicated that a person with a disability often reported low sexual esteem in comparison to people without disabilities (McCabe \& Taleporos, 2003; Taleporos \& McCabe, 2002), which was correlated, with an 
overall lower self-esteem. In a more detailed investigation of their data, McCabe and Taleporos found that this lower sexual esteem was related to the length of time that the individual had been disabled and the severity of the disability. Moreover, McCabe and Taleporos found that many of the people who participated in this study had previous experience as a TAB (temporarily able bodied person) while many people in the Deaf community have never experienced hearing and therefore often do not see themselves as disabled.

More recent work specifically focused on Deaf sexuality and has investigated intimate partner violence (IPV) among a community sample of Deaf women, finding that their rates of IPV are twice as high as those found among hearing women (Anderson \& Leigh, 2011; Barnett, Klein, Pollard, Samar, Schlehofer, Starr, \& Pearson, 2011; Pollard, Sutter, \& Cerulli, 2013; Porter \& McQuiller Williams, 2011). Porter and McQuiller Williams also found significant correlations between being Deaf or hard of hearing and having survived partner violence. Barnett and colleagues suggested that Deaf people are medically underserved, leading to overall health disparities, which may be part of the explanation for these higher rates of IPV. Anderson and Pezzarossi $(2011,2013)$ investigated whether these rates varied depending on the hearing status of the sexual partner, and confirmed that these rates reflected Deaf on Deaf violence among a college sample of Deaf women.

Looking at both girls and boys, Gomez (2011) investigated the sexual behaviors of Deaf teenagers to determine if the cultural taboos regarding Deaf teenagers having sex, inhibited sexual behaviors in Filipino Deaf high school students. Using a focus group, the participants were asked about their sexual knowledge and the age of their first sexual experiences. Findings showed that the students could define sex, describe foreplay and had knowledge of sexual signs. When asked when the participants became sexually active, the age ranged from seven years old to 25 years old. The participants reported experiences including both sexual abuse and sexual coercion. Gomez concluded that regardless of the cultural taboos, participants were sexually active with the majority of the sample reporting abuse. It should be noted that the participants did not report these early experiences as abuse, due to their lack of sexual understanding. These negative findings related to Deaf individual's sexuality tend to dominate the literature. Recently, research on more typical sexual development in Deaf college students was reported about differences in dating expectations.

\subsection{Sexual Development in Deaf and Hearing Women}

Dating is a common entry into adult sexuality, at least within American, hearing culture. Bartoli and Clark (2006) found that between the first year of college and the last two years in college that dating scripts moved from limited sexual experiences (talking for hours being the most common, ending with kissing and holding hands) to full intercourse in the later years. These behaviors are part of the Traditional Sexual Script (TSS) that is culturally transmitted (Clark, Carroll, Bartoli, \& Taylor, 2009). In a parallel study, Deaf college students shared their dating expectations, which differed from those found in Bartoli and Clark. Deaf and hard of hearing participants' expectations did not include the TSS; rather they focused more on group dating, did not mention sexual limiting by the woman, and infrequently discussed intercourse as part of a typical date (Gilbert, Clark, \& Anderson, 2012). These results are in contrast to the hearing college students' responses where all of the older students' expectations for a typical date focused on a one-on-one event between a man and a woman. The Deaf participants tended to focus on group activities and some explicitly reported that Deaf people did not date like hearing people. In addition, hearing college students all included expectations for sexual pressure for intercourse and an understanding that if the woman did not want to engage in intercourse, she must make it clear to the man that he must stop. Both hearing men and women include this expectation within their dating scripts; for the Deaf participants this sexual limiting was totally absent, as was the strong push for intercourse. These differences highlight the need for more research into the sexuality of Deaf individuals as it suggests that the TSS is culturally transmitted and it appears that Deaf individuals do not share these expectations. Therefore, one cannot assume that sexuality among deaf individuals is the same as among hearing individuals.

Sexuality and sexual satisfaction is important, as it is a large component of healthy positive adult development. Exploration of the outcomes related to sexual well-being is increasingly important, especially with the increasing number of older adults in our population (Laumann et al., 2006). Moreover, Lauman et al. discuss the importance of looking at satisfaction through happiness, peace, and fulfillment as opposed to satisfaction judgments. They suggest further research concerning older adults from a happiness and fulfillment lens to better serve this population and their psychological health. Historically, Deaf sexuality, let alone sexuality in Deaf older women, has not been looked at through this positive lens. 
Moreover, given that recent work suggests that sexuality is different in the Deaf community, we need a developmental theoretical framework. Erikson's psychosocial stages divide human development into eight stages. The second to last stage is called middle adulthood (40 to 65 years of age) and refers to a period in which people feel either generativity or stagnation. Generativity is what Erikson describes as success-a feeling of accomplishment. Someone experiencing generativity contributes to society in a meaningful and collaborative manner, whereas stagnation refers to a selfish focus and little or no desire to contribute to society (Hamacheck, 1990). The goal here is to explore how satisfaction with intimate relationships might play a role in generativity. The Centers for Disease Control and Prevention (2012a, 2012b) predicts that by 2050 there will be nearly 89 million Americans 65 and older and that there will be more than double the number of older adults who were in America in 2010. The Centers for Disease Control and Prevention (2012a, 2012b) also states that since January 2011, everyday for 20 years approximately 10,000 Americans will turn 65 years old. It appears that we need to know about older minority groups now more than ever.

\section{Research Questions}

The following questions helped guide our study:

1) How do older Deaf women describe their sexual satisfaction?

2) What is important to older Deaf women concerning their sexual satisfaction?

3) Do Deaf women show resiliency and generativity with regards to their sexuality?

\section{Analytic Design}

Using a mixed method design, Deaf women were asked to discuss their relational and sexual satisfaction across their lifespan with a focus on their later years. Initially, all participants completed a 10-item survey on sexual satisfaction. Descriptive analyses were used to determine the participants' responses to the Sexual Satisfaction Scale for Women (SSS-W: see Appendix A for the items used in the revised SSS-W) (Meston \& Trapnell, 2005), whose authors granted permission to revise this scale. In the revision, questions related to negative sexual experiences were eliminated. Immediately after completing the survey, participants were interviewed using a semistructured format (See Appendix B for a listing of the questions) with follow up questions for clarification. Grounded theory (Glaser \& Strauss, 1967) was used, including the method of constant comparisons, for the content analysis.

\section{Method}

\subsection{Participants}

Five prelingual Deaf faculty, staff, or students from Gallaudet University participated in the study. An additional participant started the study, but later asked not to be included. She was given information about the Employees Assistance Program and not included in this data. Age ranges varied from 40 to 54 years of age, with four out of the five participants in their 40s. One participant was Black ${ }^{2}$, one Bi-racial, and three were White ${ }^{3}$. Four of the participants were divorced or had ended a long-term relationship. One of the participants was a Lesbian who was not in a committed relationship, one was exploring bisexuality, and the remaining participants were in committed relationships/marriages with male partners. Three of the women had children from their current and prior marriages. Length of being in a committed relationship ranged from three years to 31 years.

\subsection{Procedures}

Participants were recruited through the use of an electronic post in the Gallaudet University school-wide message board, the Daily Digest. The Gallaudet University Institutional Review Board approved the project. The potential risks and benefits were discussed prior to engaging in the study and all participants signed an informed consent as well as a video release form to allow the interview to be videotaped and transcribed for analysis. All videos were destroyed after the transcriptions were verified, as agreed upon in the video release form.

Both researchers independently reviewed all transcripts and identified themes using the method of constant

\footnotetext{
${ }^{2}$ Black is the preferred term used by Black Deaf women.

${ }^{3}$ White is the preferred term used by White Deaf women.
} 
comparisons. Eight themes were eliminated from one reviewer's list as they were only represented in one transcript. Two additional themes were identified during a comparison of analyses, as they were more global, relating to the hearing status of partners as well as participating in group discussions with women friends. These two themes were woven throughout participants' discussions. After discussion, six overarching or global themes were identified and agreed upon, with 100 percent inter-rater reliability on identifying themes across transcripts. The four overarching themes had three to five subthemes while the global themes stood alone.

\subsection{Measures}

The SSS-W had high reliability and validity when used with hearing individuals in discriminating between clinical and nonclinical populations $(\mathrm{n}=800)$ (Meston \& Trapnell, 2005). The revised version of the SSS-W consisted of 10-items focusing on contentment, communication, and satisfaction questions from the original SSS-W. The revisions eliminated the questions related to problematic sexuality, as the goal of the study was to focus on sexual satisfaction and not problems. These more positive items were not modified and were all responded to in a consistent manner by the participants. A five-point Likert scale was used, ranging from "Strongly agree" to "Strongly disagree". Scores on three items were reverse coded for ease of analysis.

\section{Results}

\subsection{Survey Descriptives}

Results from the revised SSS-W indicate high sexual and relationship satisfaction. After reverse scoring of negatively coded items, participants' satisfaction levels were all positive, ranging from $68 \%$ to $92 \%$ satisfaction. The lower percentages were found for items indicating that something was missing from their present sex life and the level to which their partner was willing to discuss sex (see Figure 1 for a full analysis). Overall participants expressed strong communication with their partner and a positive attitude toward their own sexuality.

\subsection{Content Analysis}

Content analysis revealed four overarching themes reflected in the women's transcripts (please see Table 1). A Growth theme was noted with three subthemes of learning from previous relationships, resiliency, and gene-

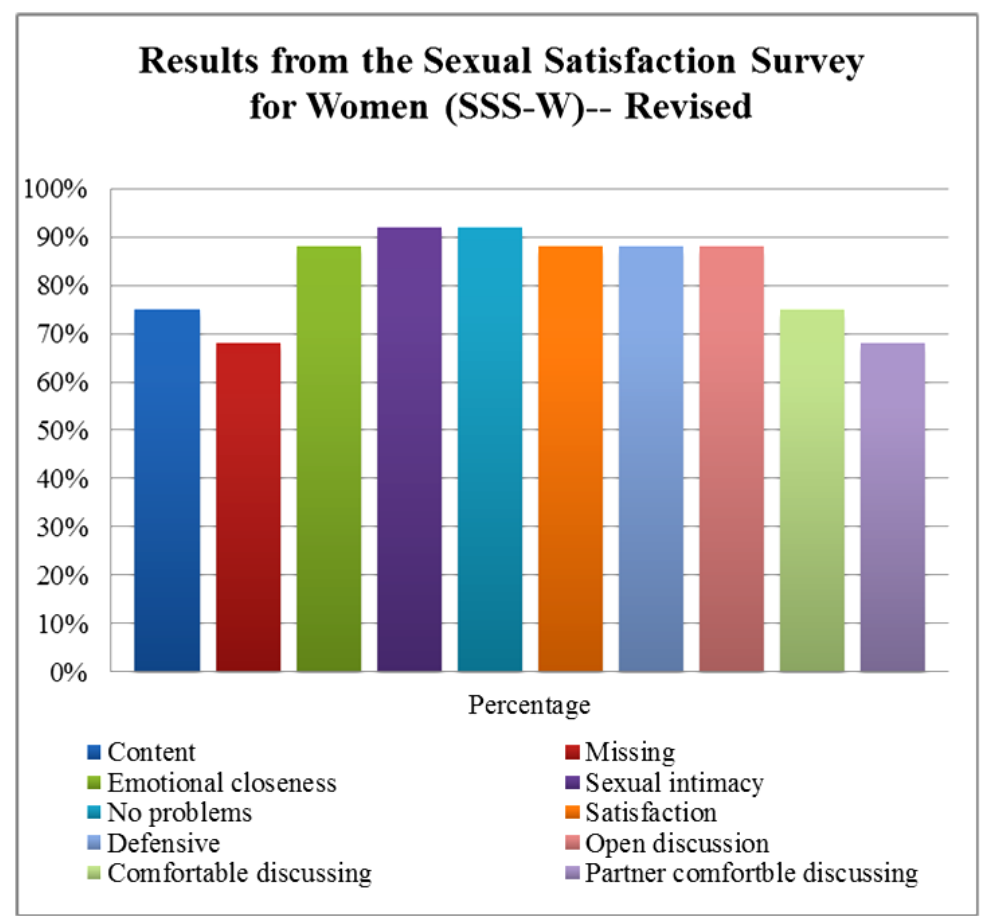

Figure 1. Results from the revised sexual satisfaction survey for women. 
Table 1. Themes indicated in participant trascripts.

\begin{tabular}{|c|c|c|}
\hline Theme & Subtheme & $\mathbf{N}$ \\
\hline \multirow{5}{*}{ Growth } & Learned from previous relationships & 5 \\
\hline & Resiliency & 4 \\
\hline & Generativity & 2 \\
\hline & Getting to know & 3 \\
\hline & Whole person & 2 \\
\hline \multirow[t]{4}{*}{ Woman's Theme } & Spirituality and intuition & 2 \\
\hline & Either trust or a lack of trust & 3 \\
\hline & Women's commitment & 2 \\
\hline & Participant cheating & 1 \\
\hline \multirow{5}{*}{ Negative Aspects of Sexuality } & Partner cheating & 1 \\
\hline & Preoccupation of the partner & 2 \\
\hline & IPV & 1 \\
\hline & Deaf culture & 3 \\
\hline & Bicultural life & 2 \\
\hline \multirow[t]{3}{*}{ Being deaf } & Deaf versus hearing partners & 5 \\
\hline & Intimacy through four senses & 4 \\
\hline & Visual communication during sex & 4 \\
\hline Exploration & & 4 \\
\hline Sex talk & & 4 \\
\hline
\end{tabular}

rativity. The next theme was labeled Woman's Theme, with five subthemes including getting to know the person prior to being in a relationship, being attracted to the whole person in a healthy relationship, using spirituality and intuition within relationships, either trust or a lack of trust within a relationship, and women's commitment to maintaining relationships. The next theme, Negative Aspects of Sexuality, included the participant cheating, their partner cheating, sexual preoccupation of the partner and IPV. A novel theme related to the cultural aspects of Being Deaf and included five subthemes: Deaf culture, bicultural life reflecting being in both the Deaf and hearing worlds, being with Deaf versus hearing sexual partners, intimacy through four senses, and the importance of visual communication during sex. Two global themes were noted. One is in terms of women Exploring all aspects of their sexuality, including their bisexuality. A second global theme emerged about Sex Talk with friends regarding their sexual experiences. This second global theme appears to cross two of the overarching themes that of the Woman's Theme and Being Deaf.

Overarching theme one: Growth. An important theme emerged regarding growth and development over the lifespan. Participants highlighted changes in their sexuality as they matured. These changes were of three kinds: the first was of learning from previous experiences and reflected strong insight among the participants. Many of the participants had left relationships that were unfulfilling, and later either found positive relationships or were looking forward to new and positive relationships. The women made the following comments:

"My values, beliefs, and behaviors might be questioned; I might ask if what I'm doing is right or wrong. I'd have to look back and analyze myself, so I'm learning. The learning never stops".

"The previous man was just young. I had just graduated and moved to New York and worked. He graduated from high school, but he was working. His goals were different than mine... I mean he was a great person, but still immature in some ways... We were just different. It was a growing process."

With more maturity, this learning was also expressed with the subtheme, resiliency. This subtheme demonstrated more insight and reflection about their past relationships which had led to new and healthy attitudes. For example, they reported:

"I'm going on with my life, I've divorced. I have a condo... I've moved on! He can't. He still wants to get back with me and I don't want to. No way!”

"My husband would abuse me... at times I was completely repulsed by the idea of sex. A few years later I met 
my current husband... he knew about my past. He didn't take it personally when I would get scared or jumpy. It's been 13 years together and we have that enjoyable sex together."

The participants who were a bit older not only showed this resiliency, but also showed the final subtheme, generativity demonstrating that their life was highly generative.

"It's important to model esteem and happiness for them [her children] and just say what it is as opposed to hiding things from them."

"Right now I want to wait before getting into a relationship. The time will come. I'll roll with that. I'll go with the flow. There's no rush, this isn't the end. While life is short, the time will come. I am patient and enjoy now."

It is evident that negative early experiences did not stifle the growth of these women. After life dealt them a weak hand, they were able to pick themselves up and take these experiences in stride. In fact, they were able to learn from them and become resilient. Moreover, these women continued to grow in ways that were contributory not only to their intimate partners, but also to people in the world around them, highlighting the overarching theme of Growth.

Overarching theme two: Woman's Theme. These women expressed traditional feminine aspects of sexuality in their interviews. Their interviews expressed wanting relationships, intimacy, trust in their partners, and being committed to their relationships. One way these characteristics were expressed was in the subtheme of getting to know their partner. Comments included:

"We would meet up as best friends in the cafeteria and have in-depth discussions. We would even have discussions and heated debates about politics. It was quite enjoyable. When we broke up he came after me trying to date and explained that if we care about each other so much as friends we should date."

"I told her that as friends we can chat, she can come to my home, chat, eat dinner and just talk. I'm not ready for a relationship so I told her I want to wait."

"No kissing or romance, just getting to know each other."

These comments reflect the aspect of emotional facilitation and relationship maintenance within the TSS. For many women, romance comes from feeling connected to the whole person, which was reflected in the subtheme of whole self. Participants made comments such as the following:

"Sometimes I can be too trusting, but I want to know about their background and if they' re honest; the whole self. Not who they are in parts. That's what I am looking for in an intimate relationship."

"It's about having someone in my life that I have intimacy with in all aspects: physical, mental, emotional, and spiritual. I really want all four of these things."

"It's important not to hide anything and look at the person in their wholeness."

Another traditional characteristic in women is intuition and spirituality, which was demonstrated in the following comments related to the subtheme of spirituality and intuition:

"I'm very connected, spiritual, I don't know. I don't know what to call it, but it's that connection."

"Oh spirituality. I'm more considerate of my inner thinking. My heart and thoughts are now connected. I don't ignore my thoughts and follow my heart and I don't ignore my heart and follow my mind. It's a connection between the two as well as the irrational and rational."

"We did kiss and that kiss was, I don't know how to describe it. The spiritual energy was like a spiritual orgasm."

Another subtheme related to traditional feminine characteristics is the ability to trust. One of our participants discussed a second date with her current husband where he blindfolded her and walked around campus. (This is a traditional activity at Gallaudet University and helps the blindfolded individual trust the person guiding them. Trust is required as it is more intense for a deaf person, because they cannot hear what is happening around them while they are blindfolded.) Another participant talked about the significance of losing trust in her husband by stating:

"I trusted him. Then when he admitted it, I lost trust. It was hard. I told him 'I can't trust him and I can't have that","

Not surprisingly trust is highly related to commitment, which is a strong component of the TSS and building relationships. Another woman described exploring sex and life with her partner who is becoming blind. Interestingly enough, the woman who talks about trust in the blindfolded date above example is the same woman who shared the comment below:

"She said, 'marriage is a witness of your life through each other.' It builds and builds to make that relatedness and intimacy. It's not just sex. It's not just physical, but also knowing each other and being best friends 
with each other. Witnessing one another...”

Additionally, another woman said: "I choose to be faithful. [In] my marriage, there's no cheating on my part."

This overarching theme is typical of women's roles in American culture. Many of the TSS roles of caring, being supportive, and loving were expressed by these five woman. The idea of "getting to know" a person related to the traditional view of women as wanting a relationship with sex as a component - but was not the most important aspect.

Overarching theme three: Negative Aspects of Sexuality. With regards to the third overarching theme of Negative Aspects of Sexuality, participants reported an interesting relationship between sexual preoccupation and either being cheated on or abused in their relationships. Even though this theme was limited within these interviews, the correlation of these subthemes seemed highly salient. The one participant who reported abuse, talked about her husband's preoccupation with all aspects of sexuality-pornography, hiring prostitutes, and coercive sex, including rape. The other participant who reported that her husband repeatedly cheated on her after promising to stop, also reported that her husband was sexually preoccupied and "needed" to have sex all of the time. The woman who reported abuse stated, "He forced me everyday." Although these behaviors did not emerge within all interviews, they reflect the themes reported by women who experience coercive sex, which can be either verbal or physical in nature. Importantly, if the woman did not report that her partner cheated or that she had been abused, she also did not reported sexual preoccupation.

Overarching theme four: Being Deaf. Another overarching theme is labeled Being Deaf to represent the aspects of being a Deaf person in contrast to a hearing person. The Deaf community is relatively small and tends to be direct in expressing their feelings. This directness is seen as support rather than as offensive. The woman related many events that demonstrated this community support in the subtheme, Deaf culture. Examples include:

“...so we had a huge celebration for him. Two weeks later someone at the party informed me, 'you know you're giving him a party, but you know he's cheating on you."”

"Right afterward I contacted DAWN [Deaf Abused Women's Network] for support because I was falling apart. So I was with DAWN for three years. They supported me throughout the first three years and throughout the court process. My advocate at DAWN was really with me throughout the process."

Another subtheme reflected both participants' desire to be part of not only the Deaf community, where ASL was important, but also being in the English dominant American culture. This subtheme was labeled bicultural life and can be seen below:

"So I might read a book to her with my voice and then sign afterward."

"To me it's important that the person has both languages, ASL and English. ASL is of paramount importance to me. I can't, I mean I know I wouldn't be happy in a monolingual relationship. I would be disappointed."

Women also discussed their sexual experiences with hearing versus Deaf individuals in the subtheme titled, Deaf versus hearing partners. All participants included comments about the differences in these relationships. Some examples included:

"The Deaf community has different norms. So dating a Deaf man means that we're a team."

"I think with our relationship, because he is Deaf too, we can both have an advantage of knowing something is wrong."

"I remember reading and discussing something with a Deaf friend. It said that Deaf with hearing people have cultural rules that differ and different perspectives or whatever. Deaf and hearing sex is different. Hearing sex is dependent on sound such as moaning, breathing, and other things. That makes or breaks sex... Deaf don't need sound. Rather we go through the body."

"He would try different positions, I would orgasm, and he was one of the best I had in some ways. Yet, communication is more important to me than just having an orgasm. I have to have that interaction and feel more connected. I have to feel more intimate. Just orgasms without dialogue are not what I want."

"When dating a hearing person they are just talking back and forth with the waiter and I feel so left out. It's a big difference."

“Those three hearing partners were the romantic type. It wasn't a hearing thing, it was their personality."

This third subtheme is similar to the next subtheme, where participants asserted that Deaf partners have intimacy through four senses. The name of this theme relates to the deaf participants awareness that sexual communication is different with a Deaf partner in contrast to a hearing partner. They emphasize the importance of their other four senses, which enhance their sexuality. One participant in discussing a relationship with a hearing 
partner mentioned how he would whisper "sweet nothings" in her ear. Her response highlights how this behavior was not romantic or sexual. In her interview she states: "I feel their whisper, but tell them, 'come on, stop it, I'm Deaf."' Other participants also mentioned the "magic" of having intimacy with four senses:

"We can have soft, loving touch, a magnetic touch where you feel love, or a strong hug not just a light and quick hug."

"Well I have more sensory feeling through my hands. Without sound the other senses increase... the physical back and forth and eye contact is different. We are excited through the eyes. Smell. Feel. Chatting."

"...contact the person, touch the person... So yes, there are advantages, Deaf Gain via sex... be observant of one another's needs, physical activity, and physical touch, and I suppose you could hear some I suppose (that's not my experience)... It's a very visual and tactile experience because you feel all over."

"My husband and I communicate in the dark. Sign on one another/back channeling. We sign big to tickle each other and make each other laugh. We communicate."

"Sign is very graphic. You can tell the person exactly what you want as opposed to talking. Rather than saying 'no, no, no' or even grab their hand and show them on your body. It's so neat. I'm used to signing. I'm used to using my hands."

"I think I'm more observant because we Deaf people depend on our eyes."

The last identified subtheme in the Deaf Being overarching theme was visual communication during sex, which was of great significance to their sexual satisfaction. They expressed this pleasure in the following:

"It's important to communicate and interact, for example it's important to check-in and make sure one another had an orgasm and we're satisfied."

"He always asks if my needs are satisfied, or if I need more."

"My marriage is so great right now! We always talk with each other to see what we like, don't like, and what we want to try. We have open dialogue."

"...you already know the lights have to be on, communication has to be clear, contact the person, and touch the person."

Overarching theme five: Exploration. There were two global themes. While these themes did not have subthemes, they were addressed by nearly all of the participants in several parts of their transcripts. The first of these global themes is Exploration of their own sexuality, including their bisexuality. These issues looked like the following:

"There's nothing wrong with my curiosity. So, I'm not sure if I'll date another woman. I haven't experienced being with a woman yet."

"There's a lot of fun. We interact and have fun. I try to satisfy him and me. We try different positions and methods."

"I had boyfriends and dated, but it was more about discovering what I like, their looks such as shape, size, strength, etc."

The participants were strongly in touch with their own sexuality. They were insightful and curious, even playful in their discussions about trying or thinking about trying new sexual experiences. They were not "turned off" by another woman's interest in them and one even mentioned, "I am not sure if she is interested." They were open to new experiences not only for themselves, but they frequently discussed that a child seemed to have interests in a member of their own sex, which was fine with the mother.

Overarching theme six: Sex Talk. The final global theme was Sex Talk. This theme reflected how women either had a best friend or more often, a group of Deaf women friends who they regularly got together with and discussed sexual well-being, sexual health, and sexual relationships. It is important to note that these group discussions were in addition to discussing sexuality with their partners.

"I'm a member of a woman's group and have been for 15 years. We have similar experiences and are all the same age. I let them know different things..."

"We were together two weeks ago discussing these issues. One person said that she had HPV and people were so surprised. I was so mad! They didn't know what HPV was, they had the wrong idea."

This global theme was found in all but one of the interviews, suggesting that these women are comfortable with their own sexuality. Several of the women have made it their life work to provide access about sexual information to Deaf women; one taught a Lamaze group and another is passionate about disseminating information about HPV. Given this goal, one woman in the interview made the following statement:

“Still I don't know enough about getting out of that relationship, addiction, family support. The Deaf commu- 
nity has even less information about these things. It's so small. I didn't know about addiction, porn, what's healthy and what's not, what to do with our children if they're sexually active, etc. There are a lot of issues that I think need addressing."

Another woman mentioned a lack of knowledge about menopause:

"There's a big barrier to information. A huge block. For example when I hit menopause, I knew that you may need medication, but that you should look into it because each person is different... It's important to get that information and share it."

This advocacy was important to some of the women in the study. All of the women were comfortable discussing sexual intimacy, even if for one participant it was more limited and with her husband of many years. This communication fits with other themes that were presented earlier relating to communication and even the willingness to discuss their own exploration of their sexuality.

\section{Discussion}

\subsection{Discussion}

Three goals motivated this study; the first was to learn how older Deaf women describe their sexual satisfaction, next was to identify what is important concerning their sexual satisfaction, and finally to see if they experience resiliency and generativity. This mixed method study showed that the women we interviewed were highly satisfied with their own sexuality and this attitude can be seen in their responses to the survey. What was important to them was finding partners who matched their own sexual needs, with whom they could be close, and share high levels of intimacy. Even participants who were not currently in a relationship reported being highly sexually satisfied. Clearly, these women were comfortable discussing sex, both with their partner and other women.

These Deaf interviewees highlighted significant experiences of growth, and expressed many ideas that are common in our beliefs about being a woman. Overall these women appear to be very comfortable with themselves and willing to share themselves with others. Many participants experienced challenges and not only overcame said challenges, but also expressed feeling very satisfied and wanting to contribute to the sexual information in the Deaf community. As Hamcheck (1990) explained, generativity means a woman feels a sense of productively contributing to society and these women, especially those who were a bit older, exhibited this generativity. Given the interviews, it would seem likely that the women who were closer to 40 years of age will become more generative after they complete their current goals of obtaining a higher education or finish raising their children.

A lack of productivity, or being stagnant, was not apparent in any of the women's narratives. Rather this group of highly educated women demonstrated resiliency and an openness to new experiences-even after earlier negative experiences. It is possible that this sample is atypical because they are highly educated, possibly making them more willing to discuss feelings, emotions, and sexuality.

Of the four overarching themes, Growth, Woman's Theme, Negative Aspects of Sexuality, and Being Deaf, two were identified more often than the others, Growth and Being Deaf. The theme that was least identified in participants' transcripts was Negative Aspects of Sexuality, which may have occurred due to the self-selection process of volunteering for a study on relationships.

A unique perspective from these interviews is how Being Deaf interacts with sexuality, as all of the participants discussed how Being Deaf relates to their sexual satisfaction, in one way or another. Regardless of whether the participant was from a Deaf or a hearing family, all five women discussed the benefits of having a Deaf partner as opposed to a hearing partner. This theme has never been discussed in the literature related to a Deaf person's sexuality. The importance of communicating visually during sex and being sexually satisfied through touch, sight, smell, and taste rather than verbally was emphasized many times and in many ways. The comment made by one participant after a hearing partner whispered in her ear is telling; "I am Deaf". Others mentioned that moaning and heavy breathing did not "turn them on" as it did for hearing women.

One thing that was noticeable, in its absence, was any discussion of being a woman. All participants discussed Deaf identity, but no one mentioned being a woman. Feminism and Women's Studies are not deeply grounded at Gallaudet University while Deaf Studies and audism (discrimination based on being Deaf) is explored in coursework and research. All participants discussed themes related to the traditional gender roles of being a woman; issues of trust, caring, and raising children, were all frequently discussed. But an identity as a woman never occurred in the interviews. Identity for Deaf individuals often focuses on being Deaf, over other identify 
issues, except for Black Deaf individuals (Myers, Clark, Musyoka, Anderson, Gilbert, Agyen, \& Hauser, 2010). Therefore, for Deaf individuals, hearing status (and ethnicity for many Black Deaf individuals) appear to be more salient than gender.

Our results indicated that these participants did not conform to the TSS (Byers, 1996), which was also found in previous research studying the TSS with Deaf women (Gilbert et al., 2012). These differences appear to be cultural and this study begins to expand some of these differences in sexual desire, sexual satisfaction, and even sexual expectations. It becomes important to fill in gaps between young and older Deaf individuals' sexuality and how Deaf culture shapes these behaviors. Future research needs to investigate these issues.

Previous research also recognized overall health disparities in the Deaf community, which they suggested may be linked to higher rates of IPV (Barnett et al., 2011). This was also indicated by participants in a call for more efficient sexual information in the Deaf community. Not only are these women currently satisfied in their sexuality and resilient over previous experiences, but they also want to give back to the community and society at large through sharing sexual information. Their efforts to improve sexual information in the community are generative all by itself.

This issue was also seen in the global theme, Sex Talk, where almost all of the interviewees participated in a regular group meeting where they discuss sex. Another theme that indicated growth and a desire to give back to their community and society at large was seen in the subtheme, learned from previous relationships as all five women indicated that they learned from what happened and many discussed how they would like to share what they learned with friends or their children.

Given how comfortable these women were in discussing their sexuality, it would not be surprising if they participated in earlier research focused on abuse, disease, and sexual education problems because they mentioned that it was nice to be asked about the positive parts of their sexuality for a change. The sex positive, generative lens helps illuminate their resiliency, growth, and contributions.

\subsection{Limitations}

While there is little research on Deaf sexuality, there is almost no research in the way of positive Deaf sexuality, making this information highly informative. However, this sample is merely reflective of five participants in the American Deaf community who are more highly educated than most Americans. Therefore, the results cannot be generalized to the larger population of Deaf women in America. Work like that of Barnet et al. (2011) and Pollard et al. (2013), who used a community sample of women is needed to help more completely understand American Deaf women's sexuality.

Additionally, understanding similarities and differences between deaf and hearing sexuality is important. As noted in Anderson and Leigh (2011), Barnett et al. (2011), Gilbert et al. (2012), and Pollard et al. (2013), there are important differences among deaf individuals-some of which are extremely dangerous to the health of $\mathrm{d} /$ Deaf women. IPV rates must be understood to reduce this health problem and the women in this study seemed aware of the need for open dialogue and honest educational information. This information needs to be discovered and presented within the Deaf community.

\subsection{Future Research}

Future research should include more participants from a variety of backgrounds that are reflective of the $d /$ Deaf community at large. Additionally, measures should be added to include an exploration of their overall life satisfaction and a more in-depth exploration of their sexual satisfaction. If future research in the area is to use mixed methods, researchers may also want to use a focus group to develop interview questions. While this study gives insight as to what questions may be important, work in this area might provide more information as to what needs to be asked.

To reach a broader community group of American Deaf women, an electronic survey may be helpful. Using a snowball technique will also be helpful in recruiting a larger sample from a variety of economic backgrounds, ethnic and racial backgrounds, as well as educational levels.

It would also be important to investigate the sexual expectations, satisfaction, and well-being and satisfaction levels of d/Deaf men to understand their own expectations with regards to this topic. Ongoing research on dating is looking at men's expectations but the data is not yet available.

It might also serve future research to explore sexual satisfaction in older Deaf women with a focus on women 
between the ages of 50 - 65. Most of the participants in the current study were in their 40s. The researchers suspect that an exploration of sexuality in Deaf women in their 50s and 60s might provide more information regarding ways that they are generative.

Lastly, following the recommendation of the women who participated in this study, there is a need for more efficient sexual information in the Deaf community. Because most of the participants shared that they regularly meet in groups to discuss sexuality another area for future research might study how Deaf women communicate about sex in groups and with friends to explore potential links between dissemination of sexual information amongst friends. Because this study is the first exploration specifically with a positive focus on how older women are sexually satisfied in the Deaf community, any work in the area could contribute to sex positive research in the Deaf community.

\subsection{Conclusion}

In summary the researchers found that the participants were resilient and generative. Unique and positive aspects to Deaf sexuality were expressed by all of the participants in this study. As such, further research in areas of sexuality and health, satisfaction, and growth will contribute to the information available regarding the Deaf community and older people and their sexual satisfaction.

\section{Acknowledgements}

The authors would like to acknowledge the support received from the Gallaudet University Small Grants for conducting this project and the Associate Provost for Research and Dean of the Graduate School as well as the Association for Women in Psychology who provided travel support to allow the first author to present part of this work at the 2014 AWP Conference in Columbus, Ohio. We would like to thank the participants for sharing the insights with us; without their help this project would not have been possible.

\section{References}

Anderson, M. L., \& Leigh, I. W. (2011). Intimate Partner Violence against Deaf Female College Students. Violence against Women, 17, 822-834. http://dx.doi.org/10.1177/1077801211412544

Anderson, M. L., \& Pezzarossi, C. M. K. (2011). Is It Abuse? Deaf Female Undergraduates’ Labeling of Partner Violence. Journal of Deaf Studies and Deaf Education, 17, 273-286. http://dx.doi.org/10.1093/deafed/enr048

Anderson, M. L., \& Pezzarossi, C. M. K. (2013). Violence against Deaf Women: Effect of Partner Hearing Status. Journal of Deaf Studies and Deaf Education, 19, 411-421. http://dx.doi.org/10.1093/deafed/ent053

Barnett S., Klein, J. D., Pollard, R. Q., Samar, V. J., Schlehofer, D., Starr, M., \& Pearson, T. A. (2011). Community Participatory Research to Identify Health Inequities with Deaf Sign Language Users. American Journal of Public Health, 101, 2235-2238. http://dx.doi.org/10.2105/AJPH.2011.300247

Bartoli, A. M., \& Clark, M. D. (2006). The Dating Game: Similarities and Differences in Dating Scripts among College Students. Sexuality and Culture, 10, 54-80. http://dx.doi.org/10.1007/s12119-006-1026-0

Byers, E. S. (1996). How Well Does the Traditional Sexual Script Explain Sexual Coercion? Review of a program of research. Journal of Psychology \& Human Sexuality, 8, 7-25. http://dx.doi.org/10.1300/J056v08n01_02

Centers for Disease Control and Prevention (2012a). Health Related Quality of Life: Nationwide Trends. http://apps.nccd.cdc.gov/HRQOL/TrendV.asp?State=1\&Category=3\&Measure=2

Centers for Disease Control and Prevention (2012b). Measuring Healthy Days. http://www.cdc.gov/hrqol/pdfs/mhd.pdf

Clark, M. D., Carroll, M. H., Bartoli, A. M., \& Taylor, M. A. (2009). Flirting to Rape: The Influence of the Traditional Sexual Script. In J. H. Ulrich, \& B. T. Cosell, (Eds.), Handbook in Gender Roles (pp. 1-32). New York: Nova Science Publishers.

Fitz-Gerald, D. and Fitz-Gerald, M. (1976). Sex Education Survey of Residential Facilities for the Deaf. American Annals of the Deaf, 121, 480-483.

Fitz-Gerald, D., \& Fitz-Gerald, M. (1978). Sexual Implications of the Deafness. Sexuality and Disability, 1, 57-69. http://dx.doi.org/10.1007/s12119-011-9111-4

Fitz-Gerald, D., \& Fitz-Gerald, M. (1985). Viewpoints: Sex Education and Deafness. Washington DC: Pre-College Programs, Gallaudet College.

Gilbert, G. L., Clark, M. D., \& Anderson, M. L. (2012). Do Deaf Individuals’ Dating Scripts Follow the Traditional Sexual 
Script? Sexuality and Culture, 16, 90-99. http://dx.doi.org/10.1007/s12119-011-9111-4

Glannon, C. (1998). The Deaf Community and Sexuality Education. Sexuality and Disability, 16, 4. http://search.proquest.com/docview/235707658

Glaser, B., \& Strauss, A. (1967). The Discovery of Grounded Theory. London: Weidenfield \& Nicolson.

Gomez, M. (2011). Sexual Behavior among Filipino High School Students Who Are Deaf. Sexuality and Disability, 29, 301312.

Hamachek, D. (1990). Evaluating Self-Concept and Ego Status in Erikson's Last Three Stages. Journal of Counseling and Development, 68, 6.

Job, J. (2004). Factors Involved in the Ineffective Dissemination of Sexuality Information to Individuals Who Are Deaf or Hard of Hearing. American Annals of the Deaf, 149, 264-273. http://library.ncrtm.org/pdf/J305.1493.01B.pdf http://dx.doi.org/10.1353/aad.2004.0025

Joseph, J. M., Sawyer, R., \& Desmond, S. (1995). Sexual Knowledge, Behavior and Sources of Information among Deaf and Hard of Hearing College Students. American Annals of the Deaf, 140, 338-345. http://dx.doi.org/10.1353/aad.2012.0379

Kamieka, G., \& Getch, Y. (2001). Parental Training and Involvement in Sexuality Education for Students Who Are Deaf. American Annals of the Deaf, 146, 3. http://search.proquest.com/docview/214478234

Laumann, E. O., Paik, A., Glasser, D. B., Kang, J. H., Wang, T., Levinson, B., \& Gingell, C. (2006). A Cross-National Study of Subjective Sexual Well-Being among Older Women and Men: Findings from the Global Study of Sexual Attitudes and Behaviors. Archives of Sexual Behavior, 35, 143-159. http://dx.doi.org/10.1007/s10508-005-9005-3

McCabe, M. P., \& Taleporos, G. (2003). Sexual Esteem, Sexual Satisfaction, and Sexual Behavior among People with Physical Disability. Archives of Sexual Behavior, 32, 359-369. http://proxyga.wrlc.org/login?url http://search.proquest.com/docview/205935170?accountid=27346

Meston, C., \& Trapnell, P. (2005). Development and Validation of a Five-Factor Sexual Satisfaction and Distress Scale for Women: The Sexual Satisfaction Scale for Women (SSS-W). Journal of Sexual Medicine, 2, 66-81.

http://www.ncbi.nlm.nih.gov/pmc/articles/PMC2859306/ http://dx.doi.org/10.1111/j.1743-6109.2005.20107.x

Myers, C., Clark, M. D., Musyoka, M. M., Anderson, M. L., Gilbert, G. L., Agyen, S., \& Hauser, P. C. (2010). Black Deaf Individuals' Reading Skills: Influence of ASL, Culture, Family Characteristics, Reading Experience, and Education. American Annals of the Deaf, 155, 449-457.

Omansky, B. G., \& Rosenblum, K. E. (2001). Bringing Disability into the Sociological Frame: A Comparison of Disability with Race, Sex, and Sexual Orientation Statuses. Disability and Society, 16, 5-19. http://dx.doi.org/10.1080/713662032

Pollard, R., Sutter, E., \& Cerulli, C. (2013). Intimate Partner Violence Reported by Two Samples of Deaf Adults via a Computerized American Sign Language Survey. Journal of Interpersonal Violence, 29, 948-965. http://dx.doi.org/10.1177/0886260513505703

Porter, J. L., \& Williams, L. M. (2011). Intimate Violence among Underrepresented Groups on a College Campus. Journal of Interpersonal Violence, 26, 3210-3224. http://dx.doi.org/10.1177/0886260510393011

Robinson, L. D. (1979). Sexuality and the Deaf Culture. Sexuality and Disability, 2, 161-168. http://dx.doi.org/10.1007/BF01100787

Rohleder, P., \& Swartz, L. (2011). Disability, Sexuality and Sexual Health. In P. Aggleton, P. Boyce, H. L. Moore, \& R. Parker, (Eds.), Understandin Global Sexualities: New Frontiers (pp. 138-152). New York: Routledge.

Swartz, D. B. (1993). A Comparative Study of Sex Knowledge among Hearing and Deaf College Freshman. Sexuality and Disability, 11, 129-147. http://dx.doi.org/10.1007/BF01102192

Taleporos, G., \& McCabe, M. P. (2002). The Impact of Sexual Esteem, Body Esteem, and Sexual Satisfaction on Psychological Well-Being in People with Physical Disability. Sexuality and Disability, 20, 177-183.

http://dx.doi.org/10.1023/A:1021493615456 


\section{Appendix A}

1) I feel content with the way my present sex life is.

2) I often feel something is missing from my present sex life.

3) I often feel I don't have enough emotional closeness in my sex life.

4) I feel content with how often I presently have sexual intimacy (kissing, intercourse, etc.) in my life.

5) I don't have any important problems or concerns about sex (arousal, orgasm, frequency, compatibility, communication, etc.).

6) Overall, how satisfactory or unsatisfactory is your present sex life?

7) My partner often gets defensive when I try discussing sex.

8) My partner and I do not discuss sex openly enough with each other, or do not discuss sex often enough.

9) I usually feel completely comfortable discussing sex whenever my partner wants to.

10) My partner usually feels completely comfortable discussing sex whenever I want to.

\section{Appendix B}

\section{Interview Questions}

1) Are you currently in a romantic or intimate relationship(s)?

a) If not, when was your last relationship? How long was it?

2) How many sexual or intimate partners have you had in your lifetime?

3) What do you like about your intimate relationships?

4) How satisfied have you been in your previous and current intimate relationships?

5) What did or does your intimate relationship add to your life?

6) Regardless of your current relationships, would you like to be in a intimate relationship?

7) Are there any differences related to being in an intimate relationship with a hearing or $d /$ Deaf partner?

8) What experiences, if any of being $d /$ Deaf has added to your intimate relational satisfaction?

9) What experiences, if any of being $d /$ Deaf has added to your sexual satisfaction? 
Scientific Research Publishing (SCIRP) is one of the largest Open Access journal publishers. It is currently publishing more than 200 open access, online, peer-reviewed journals covering a wide range of academic disciplines. SCIRP serves the worldwide academic communities and contributes to the progress and application of science with its publication.

Other selected journals from SCIRP are listed as below. Submit your manuscript to us via either submit@scirp.org or Online Submission Portal.
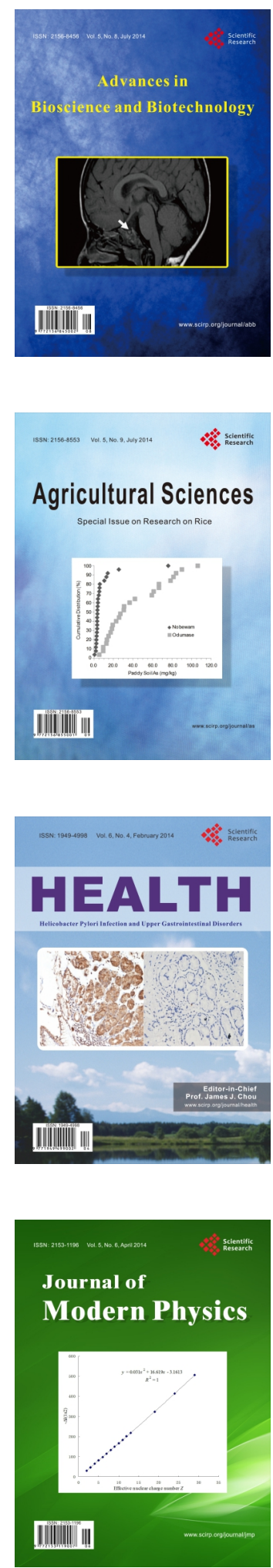
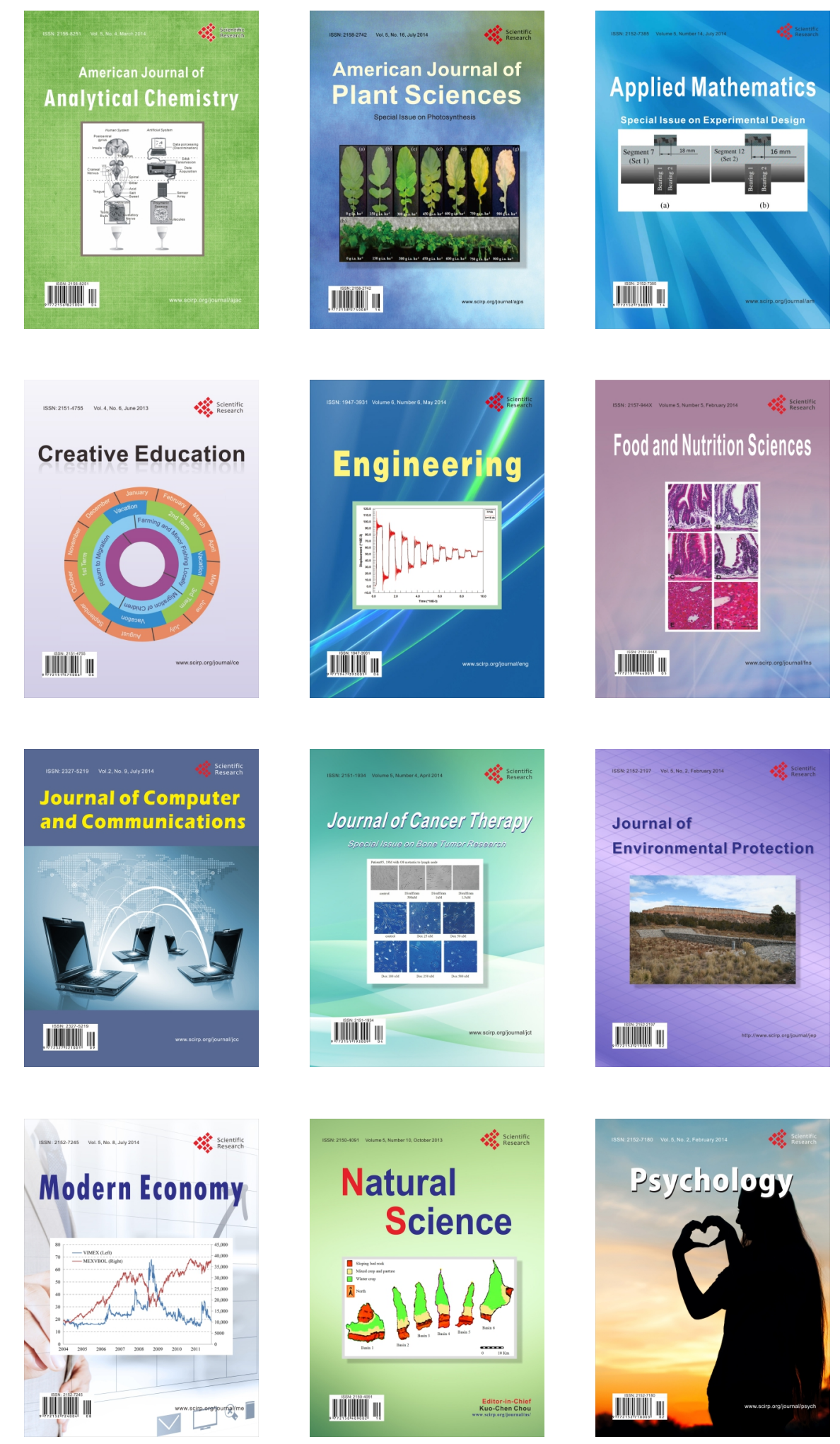